\section{Ole e 10 - neues pan-allergenes Protein}

\author{
Auf der kontinuierlichen Suche nach der molekularen Struktur \\ wichtiger Allergene hat eine spanische Arbeitsgruppe ein bisher \\ unbekanntes Allergen aus Olivenpollen identifiziert.
}

\begin{abstract}
ie wichtigsten bekannten Allergene aus Olivenpollen sind Ole e 1 und Ole e 9. Mit dem nun identifizierten Ole e 10 wurde ein weiteres Hauptallergen gefunden - über 50\% der Olivenallergiker scheinen dagegen sensibilisiert $\mathrm{zu}$ sein. Das neue Allergen ist relativ klein $(10,8 \mathrm{kDa})$ und besteht aus einer einzelnen Polypeptidkette mit 102 Aminosäuren. Die Sekundärstrukturanalyse ergab zu $17 \%$ eine $\alpha$-Helix, zu 33\% ein $\beta$-Faltblatt und $\mathrm{zu} 21 \% \quad \beta$-Schleifen. Die C-terminale Domäne gleicht der von Ole e 9. Die Datenbanksuche nach weiteren Proteinhomologien zeigte Übereinstimmung mit Proteinen aus Arabidopsis thaliana (42-46\% Identität, abgeleitet aus der Gensequenz) und mit Polypeptid-Segmenten von Proteinen,
\end{abstract}

die bei der Entwicklung von Hefen eine Rolle spielen (42-43\% Ähnlichkeit).

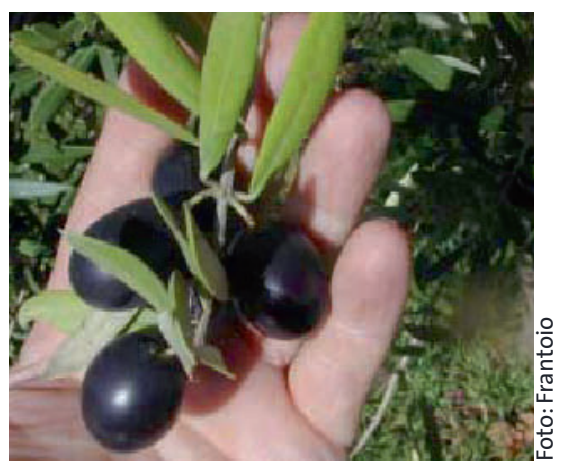

Sensibilisierungen gegen die Pollen von Olivenbäumen sind nicht nur im mediterranen Raum, sondern auch in Teilen der USA, Südamerikas, Südafrikas und Australiens ein häufiger Allergieauslöser.
Ole e 10 hat eine hohe IgE-Kreuzreaktivität mit Ole e 9 und besitzt vergleichbare IgE-B-Zell-Epitope wie andere Pollenproteine von Pflanzen z. B. aus den Familien der Oleaceae, Betulaceae oder Cupressaceae oder wie in den Pollen von Parietaria und Ambrosia. Auch mit Naturlatex und Gemüse oder Früchten wie Tomaten, Kiwi oder Kartoffeln besteht Kreuzreaktivität.

Fazit: Das neu entdeckte Ole e 10 ist ein weiteres Hauptallergen aus Olivenpollen. Mit seiner vielfältigen Kreuzreaktivität mit Allergenen aus der Familie der Oleaceae wie auch aus anderen Pflanzenfamilien kann es als pan-allergenes Protein bezeichnet werden. Eventuell spielt es eine zentrale Rolle bei Kreuzreaktivität auf Naturlatex, Früchte und Pollen. $\quad b k$

Barral $P$ et al. A major allergen from pollen defines a novel familiy of plant proteins and shows intra- and interspecies cross-reactivity. J Immunol 2004; 172: 3644-51

\title{
Molekulare Mimikry mit Kuhmilchprotein
}

\section{Molekulare Mimikry ist ein Phänomen, mit dem das Entstehen von Autoimmunerkrankungen erklärt werden kann - zumindest in der Theorie. In einer experimentellen Arbeit wird jetzt das Vor- liegen einer humoralen Kreuzreaktion auf körpereigenes Protein und Nahrungsmittelantigenen beschrieben.}

ei der molekularen Mimikry kommt es zu einer antikörperbasierten Kreuzreaktion gegen die Epitope chemisch sehr ähnlicher Molekülsequenzen bei einem Fremdantigen und bestimmten körpereigenen Strukturen. Eine solche humorale Kreuzreaktion wird ätiologisch beispielsweise bei verschiedenen neurologischen Autoimmunerkrankungen wie dem Guillain-Barré-Syndrom und der multiplen Sklerose (MS) diskutiert. Als Fremdantigene kommen hierbei vor allem Viren in Frage, deren Proteinstrukturen teilweise denen von Myelinproteinen ähneln.

Dass eventuell auch Antigene aus der Nahrung an der Autoimmungenese der MS beteiligt sein könnten, ließen epidemiologische Studien erahnen, die wiederholt auf einen Zusammenhang zwischen dem Konsum von Milchprodukten und dem Auftreten von MS berichteten. Als molekularer Mechanismus bietet sich molekulare Mimikry zwischen den von den Oligodendrozyten des ZNS synthetisierten MyelinOligodendrozyten-assoziierten Glykoproteinen (MOG) und dem Kuhmilchprotein Butyrophilin (BTN) an. Dieser Befund lässt sich zumindest aus den Analysen von MOG-spezifischen Autoantikörpern aus den Seren von MS-Patienten ableiten. Diese MOG-spezifischen Autoantikörper können nämlich mit verschiedenen Peptid-Epitopen von BTN kreuzreagieren, außerdem konn- ten in der zerebrospinalen Flüssigkeit der MS-Patienten BTN-reaktive Antikörper nachgewiesen werden.

Die Sensibilisierung gegen das Kuhmilchprotein könnte bei einem Ausfall der normalerweise vorhandenen oralen Toleranz entstanden sein, wie sie z. B. bei gastrointestinalen Infekten beobachtet wird. Auch bei noch gestillten Säuglingen ist die orale Toleranz nicht voll entwickelt.

Fazit: Antigene aus der Nahrung könnten über Mechanismen der molekularen Mimikry zu einer Abwehrreaktionen gegen körpereigene Proteine führen und damit eine Autoimmunreaktion anstoßen. Eine solche antikörperbasierte Kreuzreaktion gegen ein Kuhmilchprotein und Glykoproteine der Myelinscheiden wurde jetzt bei MS-Patienten nachgewiesen.

Guggenmos J et al. Antibody cross-reactivity between myelin oligodendrocyte glycoprotein and the milk protein butyrophilin in multiple sclerosis. J Immunol 2004; 172: 661-8 